\title{
Permeability of the Hydrated Shale under Cyclic Loading and Unloading Conditions
}

\author{
Liu Xianshan $\mathbb{D}^{1,2}$ Li Man, ${ }^{1,2}$ Xu Ming, ${ }^{1,2}$ and Kang Zhiyong ${ }^{1,2}$ \\ ${ }^{1}$ Key Laboratory of New Technology for Construction of Cities in Mountain Area (Chongqing University), Ministry of Education, \\ Chongqing 400045, China \\ ${ }^{2}$ School of Civil Engineering, Chongqing University, Chongqing 400045, China
}

Correspondence should be addressed to Liu Xianshan; lzmoumou@163.com

Received 9 June 2020; Revised 28 July 2020; Accepted 8 August 2020; Published 7 September 2020

Academic Editor: Wei Wei

Copyright (c) 2020 Liu Xianshan et al. This is an open access article distributed under the Creative Commons Attribution License, which permits unrestricted use, distribution, and reproduction in any medium, provided the original work is properly cited.

The hydrated shales under cyclic loading and unloading conditions are common for the shale reservoir development; corresponding mechanical properties and permeability evolution are very significant and should be deeply researched. Firstly, the experiments of the hydrated shales under the above conditions are discussed, showing that the peak strength is lower and corresponding permeability is higher for more days of hydrating treatment. Secondly, the damage theory is proposed to analyze the shale permeability evolution due to hydromechanical damage and get permeability variation under initial loading and unloading conditions, observing that the permeability in the loading process decreases with increasing confining pressure and increases in the unloading process with decreasing confining pressure; however, the former changes much greater than the latter considering the same confining pressure, indicating that the irreversible damage for the hydrated shales in this cyclic condition has resulted in obvious difference of the permeability. Furthermore, the curves between the permeability and confining pressure based on the experimental data are fitted as negative exponential functions under initial loading conditions and power functions under more cyclic loading conditions, showing that more loading process will change the permeability evolution model. However, the permeability while unloading changes smoothly and can be fitted as a power function with the confining pressure. And in addition, the loss ratio and recovery ratio of the permeability have been deeply researched under five cyclic loading and unloading conditions, thoroughly explaining the permeability decreasing variation with more cyclic processes. Finally, the sensitive coefficients of the permeability have been investigated to observe the largest coefficients under initial cyclic conditions and less and less with more cyclic processes, especially the coefficients while loading which are more sensitive to lower confining pressure and smaller while unloading, which is in accordance with the shale permeability loss and recovery variation, revealing the permeability evolution of the hydrated shale under complex extracted environment.

\section{Introduction}

China Mineral Resources (2018) has reported that accumulated proven geological reserves of shale gas from 2015 to 2017 are, respectively, 5441, 7643, and 9168 billion cubic meters, and corresponding productions are, respectively, 45, 78.82 , and 100 billion cubic meters. The shale gas production in China has gradually increased in recent years, but the recovery efficiency is still lower than that in America; the reservoir permeability as an important index is significant for deeply understanding the exploration mechanism. However, the shale reservoir influenced by deposition and the tectonic movement includes orientated clay mineral and different pore structures, causing significant anisotropy and heterogeneity [1] for extracting gas more difficult. As for the drilling process, the drilling fluid hydrating the shale repeatedly will weaken the mechanical parameters and enlarge the seepage channels, resulting in instability of the well wall. Note that the failure of reservoir shale and corresponding permeability variation in the process $[2,3]$ is a potential instance considered in the gas engineering. Especially, the noted hydration effect will cause vague variation of the mechanical and permeable properties of the shales, drastically enhancing the difficulty of shale gas development. Therefore, deep research on 
the permeability of hydrated shale under complex extracting circumstances has attracted attentions by many researchers.

In recent years, a few researches about the hydrated shale with the help of the advanced equipment have been investigated. Shi and Xia [4] observed the variation of the shale structure by XRD, SEM, and CT, indicating that the water weakening minerals caused crack propagation, and $\mathrm{Ma}$ and Chen [5] conducted hydration experiment by CT and observed that obvious damage was mainly in the initial hydrated stage; also, Liu et al. [6] used SEM to observe the microcrack propagation to form the large fractures when hydrating much more time. Massat et al. [7] carried out experiments to research on hydration influence on the shale structures and pore distribution, mainly causing the crack propagation, and Liu et al. [8] pointed out that arranged mineral particles provided channels for shale absorbing water when hydrating to change corresponding structures. The above experiments show that hydration greatly changes the shale microstructure to influence on its mechanical characteristics, so the issue about the properties of the hydrated shale should be solved in detail. Zhang and Sheng [9] analyzed the crack propagation and gave the relationship of the hydration expansion stress and seepage parameters. Teng et al. [10] researched the elastic modulus and strength decreasing variation with long hydrating time. Zhu et al. [11] explained that mechanical parameters of the hydrated shale decreased because of corresponding clay structures changing into flocculent fabrics. Roshan et al. [12] also carried out physical and chemical analysis to illuminate the mineral hydration influence on the shale permeability. Zhang and Sheng [13] compared the shale permeability variation considering water and KCL treatment, showing that water hydration affected the shale permeability more greatly. The above studies indicate that the hydration effect on the mechanical and permeable properties in laboratory conditions and in situ compression tests should not be ignored, and deep investigations about complex load combination on the hydromechanical behavior of the reservoir shales should be deeply conducted.

In decades, some researchers have paid more attentions to the rock permeability under different loading conditions. Tan et al. [14] determined the relationship of the rock permeability and corresponding axial strain in the process of the progressive failure, indicating the complex hydromechanical coupled behavior of low porous rocks; Zhou et al. [15] discussed the shale permeability evolution considering different combinations of the shale structures and different confining pressures; Liu [16] analyzed the shale deformation and corresponding permeability variation and proposed a permeability model considering rock damage evolution; and Yu et al. [17] conducted the permeability tests under loading and unloading conditions, showing that the permeability after unloading sharply increased and the value reached to the maximum considering unloading confining pressure at the prepeak. The above researches about the permeability evolution under single loading or unloading condition give supports to investigate the permeability variation under cyclic loading and unloading conditions. And also, some researches have been implemented. Yu et al. [18] conducted the seepage experi- ments to describe the permeability variation of sandstones under freeze-thaw loading conditions; Yin et al. [19]; Xu et al. [20], and Pan et al. [21] researched the coal permeability under a combination of the axial and confining pressure and gave the theoretical analysis; and Kong et al. [22] found out that the permeability evolution curve under loading conditions could not match that in the process of unloading. Zhang et al. [23] conducted the periodic seepage tests of the sandstones in the Three Gorges Reservoir, showing that permeability is approaching a stable value under four cyclic loading and unloading conditions. Sun et al. [24] determined the dynamic permeability model considering cyclic axial stress. Wang et al. [25] carried out the three-axial cyclic loading tests to investigate the relationship of the coal permeability and damage energy. Therefore, researches about the permeability characteristics of the reservoir shale under complex loading and unloading conditions should be deeply investigated. Sun et al. [26] and Yan et al. [27] carried out the seepage tests to reveal the strong relationship of shale permeability and real-time damage, providing useful information for research on the permeability characteristics of hydrated shale under cyclic loading and unloading conditions.

Therefore, taking a reservoir shale as a case study, considering the shale structures and hydration effect, corresponding permeability experiments under cyclic loading and unloading conditions are conducted to investigate the relationship of crack propagation and permeability of reservoir shales. And also, the damage analysis has been proposed to analyze the shale damage evolution and corresponding permeability variation, revealing the permeability characteristics caused by progressive damage considering the hydromechanical coupling effect. Furthermore, some models describing the permeability loses, permeability recoveries, and corresponding stress-sensitive coefficients are proposed to indicate the permeability evolution under cyclic loading and unloading conditions, revealing the permeability evolution mechanism of the hydrated shale under complex conditions.

\section{Seepage Experiments of the Hydrated Shale}

2.1. Sample Preparation. To investigate the permeability characteristics of hydrated reservoir shales under cyclic loading and unloading conditions, the testing shales are the outcrop taken from Longmaxi in Chongqing Shizhu county, which are selected for the permeability experiments. Firstly, the mineral composition of the pulverized shale should be analyzed based on XRD to get the diffraction pattern as Figure 1(a), showing the minerals of Quartz, orthoclase, plagioclase, calcite, dolomite, illite, montmorillonite, chlorite, and kaolinite. And according to the method by the International Society for Rock Mechanics (ISRM), the size of all tested specimens is cylindrical with $50 \mathrm{~mm}$ diameter and $100 \mathrm{~mm}$ length approximately, shown in Figure 1(b). It is observed from Figure 1(b) that the shales are black with obvious bedding. Furthermore, acoustic emissions from all specimens are detected and received by the nonmetallic acoustic detector RSM-SY5 in order to illuminate that every group of reservoir sandstone specimens is uniform to avoid the 


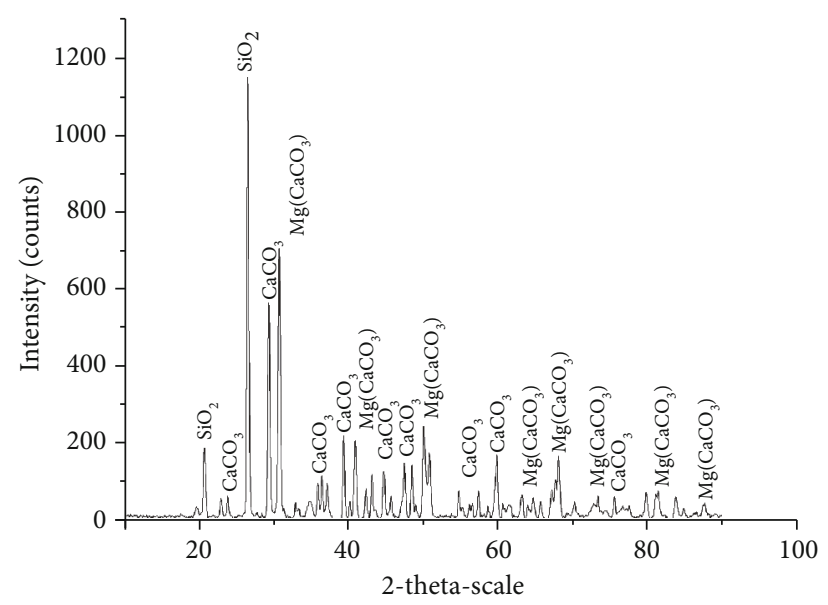

(a)
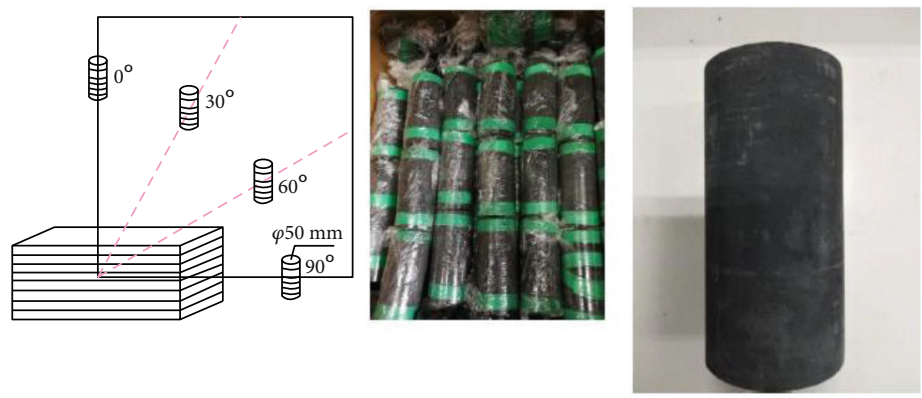

(b)

FIgURE 1: The shale samples and corresponding XRD. The labels are in Figure 1 as follows, Fig.1(a)Diffraction pattern of the shale based on XRD.Fig.1(b) Arranged shale samples.

specimen heterogeneity influencing on the experimental efficiency and accuracy.

2.2. Apparatus for Shale Seepage Experiments. All the seepage experiments will be conducted in Geotechnical Test Center of Chongqing University, and a rock servo-controlled triaxial equipment named Rock 600-50HT PLUS manufactured by TOP-INDUSTRIE in France is arranged for all the tests.

The experimental apparatus consists of a hydraulic pressure transfer system, a pressure chamber equipment, a hydraulic pressure system, and an automatic data collection system; performing triaxial compression tests at confining pressures (P2) up to $60 \mathrm{MPa}$, with increasing deviatoric stress (P1) up to $500 \mathrm{MPa}$ and with an increasing transducer, has a resolution of $0.01 \mathrm{MPa}$. And the system can handle the constant-head, constant flow-rate, and transient-pulse permeability tests under low or high confining and water pressures. Also, different fluids can be chosen as the testing fluid and the servo-controlled fluid pump can regulate the pore pressure up to $60 \mathrm{MPa}(\mathrm{P} 3 / \mathrm{P} 4)$ according to the experimental target.

This apparatus can perform mechanical tests, seepage tests, and hydromechanical tests by computer and robotized operations, ensuring that all the testing data can be analyzed safely, timely, and accurately. The apparatus can be used to deal with hydrostatic pressure tests, triaxial seepage tests, etc. Four kinds of loading modes including displacement loading, stress loading, strain loading, and flow loading are employed to satisfy different experimental requirements. And the apparatus can automatically record all the realtime data every 5 seconds.

2.3. Testing Theory and Design. Firstly, the hydrated shales have been treated with 0 days (no hydration), 2 days, 5 days, and 10 days, shown in Figure 2, and obvious cracks are observed on the shale surface with more hydrated days. When conducting the shale seepage tests, the shale specimens are enclosed in a $3 \mathrm{~mm}$ thick Viton rubber jacket and then placed in the sample assembly. When testing, the axial displacement is measured with two displacement LVDTs, and the circumferential deformation is measured with a circumferential sensors. Considering the temperature influencing on the shale deformation and seepage characteristics, all the tests are conducted at room temperature $\left(25 \pm 2^{\circ} \mathrm{C}\right)$.

And then, corresponding tests of the hydrated shales under different load combinations are performed. For obtaining the damage variation and permeability characteristics of the hydrated shale, the samples are firstly conducted with desired confining pressure, and the axial stress is proportionally increased to the value of the confining pressure to ensure an initial isotropic stress or zero deviatoric stress. In addition, the upstream pressure (P3) and downstream pressure (P4) are balanced for the hydrated shales to ensure the fluid in a single phase. Afterwards, the deviatoric stress is increased stepwise and the seepage testing is invoked for measurements of the rock permeability. For this seepage 


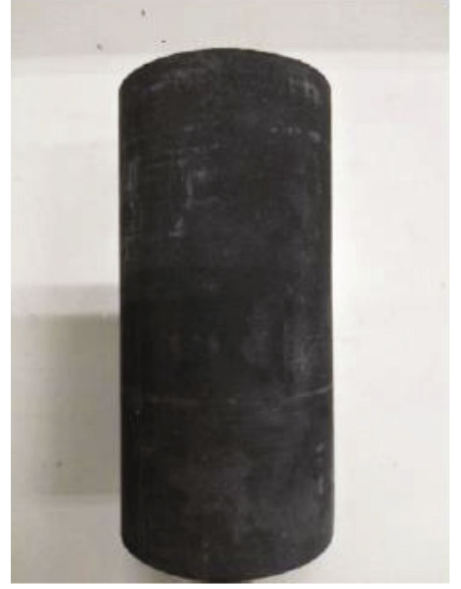

(a)

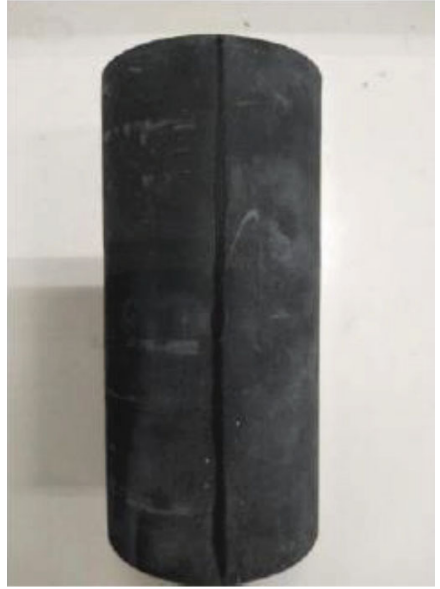

(b)

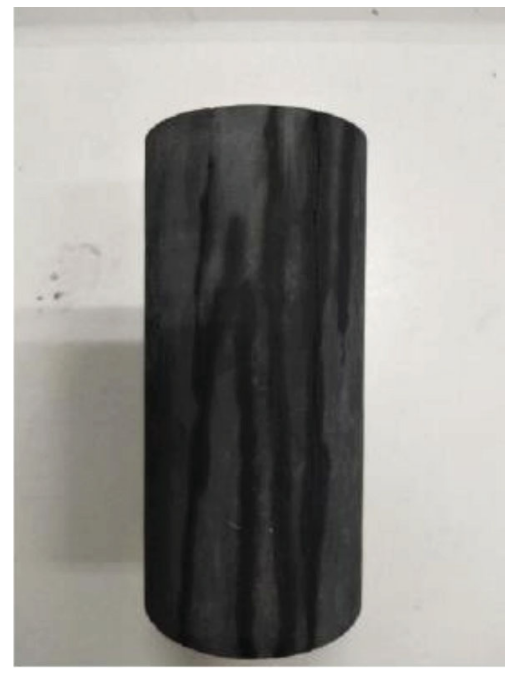

(c)

Figure 2: The shale samples with different hydrating days. The labels in Fig.2 are as follows, (a)No hydration (b) 2 days (c)5 days (d) 10 days.

testing procedure, the permeability of the samples can be calculated by measuring the fluid volume from the pump in a period of time and written by [16]

$$
k=\frac{\mu L V}{A \Delta p \Delta t},
$$

where $k$ is the shale permeability $\left(\mathrm{m}^{2}\right), \mu$ is the fluid dynamic viscosity (water at $T=20^{\circ} \mathrm{C}, 1 \times 10^{-3} \mathrm{~Pa} \cdot \mathrm{s}$ ), $L$ is the shale specimen height $(\mathrm{m}), V$ is the fluid volume $\left(\mathrm{m}^{3}\right)$ from the pump in time $\Delta t, A$ is the cross-sectional area $\left(\mathrm{m}^{2}\right), \Delta p$ is the fluid pressure difference $(\mathrm{Pa})$, and $\Delta t$ is the flow time(s).

As for the seepage tests under cyclic loading and unloading conditions, the detailed design is listed in Table 1. The design considers seepage pressure $4 \mathrm{MPa}$ and axial pressure $5 \mathrm{MPa}$ and confining pressure loading from $5 \mathrm{MPa}$ to $11 \mathrm{MPa}$ and unloading from $11 \mathrm{MPa}$ to $5 \mathrm{MPa}$ (increment of $1 \mathrm{MPa}$ ) for five times, and permeability of the hydrated shales under different stages can be measured, describing the permeability variation with different hydrated days under designed load conditions.
TABLE 1: The seepage tests of the hydrated shale under cyclic loading and unloading conditions.

\begin{tabular}{|c|c|c|c|}
\hline \multirow{2}{*}{$\begin{array}{l}\text { Seepage } \\
\text { pressure } \\
(\mathrm{MPa})\end{array}$} & \multirow{2}{*}{$\begin{array}{c}\text { Axial } \\
\text { pressure } \\
(\mathrm{MPa})\end{array}$} & \multirow{2}{*}{$\begin{array}{l}\text { Hydration } \\
\text { time }(\mathrm{d})\end{array}$} & $\begin{array}{c}\text { Confining pressure } \\
(\mathrm{MPa})\end{array}$ \\
\hline & & & $\begin{array}{lllllll}5 & 6 & 7 & 8 & 9 & 10 & 11\end{array}$ \\
\hline \multirow{4}{*}{4} & \multirow{4}{*}{5} & 0 & \multirow{4}{*}{$\begin{array}{l}\text { Cyclic loading and } \\
\text { unloading condition }\end{array}$} \\
\hline & & 2 & \\
\hline & & 5 & \\
\hline & & 10 & \\
\hline
\end{tabular}

\section{Permeability Analysis of the Shale with Different Hydrated Time}

3.1. Mechanical Characteristics and Permeability Variation of the Hydrated Shale. In order to describe the mechanical characteristics and corresponding permeability variation of the hydrated shale with different days (2 days, 5 days, and 10 days), the curves of the deviatoric stress and strain and 


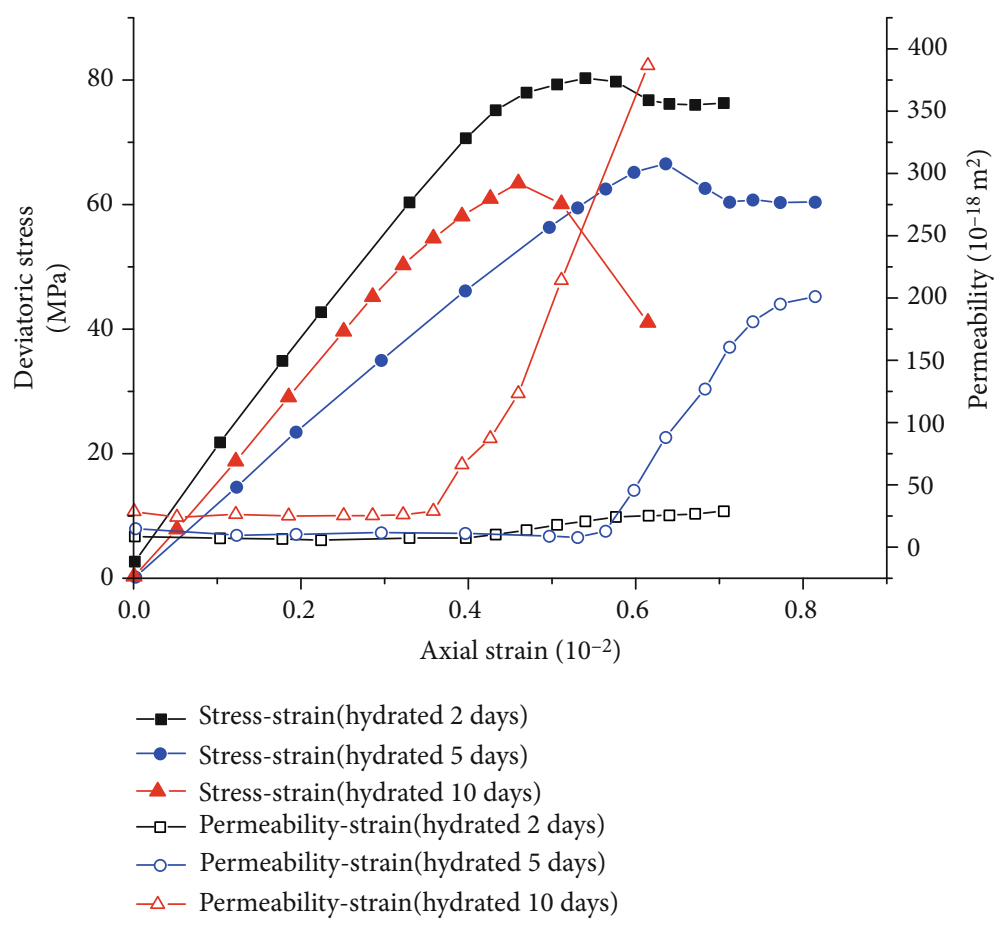

FIgURE 3: The curves of stress and permeability variation.

permeability and strain considering the load combination of seepage pressure $4 \mathrm{MPa}$ and confining pressure $5 \mathrm{MPa}$ are shown in Figure 3. It can be seen that the variation patterns of the deviatoric stress and strain are similar; however, the shale treated by more hydrated days shows lower peak strength. According to the hydrated characteristic shown in Figure 2, it can be concluded that there is more water absorption into the shale with more hydrated days, causing the mineral expansion and separation to generate the flocculent fabrics and larger pore structure, so the water can flow into the pores and fractures more and more to enlarge the shale damage. Therefore, the shale specimen with more hydrated days generated more cracks quickly to propagate under progressive loading conditions [28], especially the shale bedding which was softened and lubricated to weaken the rock strength and failed more easily.

Furthermore, the permeability evolution under different combinations of confining pressure and different water pressures is plotted in Figure 3, showing that given the same loading conditions, the permeability of given hydrated days decreased in the initial loading stage and then increased with increasing loads; the variation was in accordance with the above stages of the shale crack propagation and permeability evolution in reference [26], deeply calibrating the synchronism of the permeability evolution with the crack initiation and propagation. Also, it can be seen from Table 2 that the initial permeability of the shale with hydration for 0 days, 2 days, 5 days, and 10 days, respectively, $6.63 \times 10^{-18} \mathrm{~m}^{2}$, $8.69 \times 10^{-18} \mathrm{~m}^{2}, 14.65 \times 10^{-18} \mathrm{~m}^{2}$, and $26.58 \times 10^{-18} \mathrm{~m}^{2}$, indicating that the permeability of the shale with more hydrated days in the initial compaction stage is larger because of more cracks mentioned in Figure 2. And increasing ratio of shale
TABLE 2: The permeability considering hydraulic pressure with different confining pressures $\left(10^{-18} \mathrm{~m}^{2}\right)$.

\begin{tabular}{lcccc}
\hline Hydrated days (day) & 0 & 2 & 5 & 10 \\
\hline Initial permeability & 6.63 & 8.69 & 14.65 & 26.58 \\
Minimum permeability & 3.31 & 3.52 & 6.49 & 12.54 \\
Maximum permeability & 29.57 & 39.54 & 201.55 & 386.71 \\
\hline
\end{tabular}

permeability considering hydrated days from 0 days to 2 days, 2 days to 5 days, and 5 days to 10 days is, respectively, $31.07 \%, 68.58 \%$, and $81.43 \%$, the comparison showing that the permeability is more sensitive to the hydrated period. So the permeability variation can explain that long-time hydration causes much more pores and propagated cracks to enlarge the seepage channels, resulting in the permeability increasing greatly. Therefore, observations from the above data indicate that the hydration should not be ignored for the reservoir drilling and hydraulic fracturing in the process of shale gas extraction.

And also, corresponding minimum permeability of shales with no hydration, hydrated 2 days, 5 days, and 10 days under the same load condition, respectively, with values $3.31 \times 10^{-18} \mathrm{~m}^{2}, 3.52 \times 10^{-18} \mathrm{~m}^{2}, 6.49 \times 10^{-18} \mathrm{~m}^{2}$, and 12.54 $\times 10^{-18} \mathrm{~m}^{2}$, is also listed in Table 2. It can be observed that the minimum permeability of shales also increased with more hydrated days, showing that more and greater cracks of shales with long period of hydration still dominate. In addition, the corresponding maximum permeability is listed in Table 2, and the corresponding values are $29.57 \times 10^{-18} \mathrm{~m}^{2}$, $39.54 \times 10^{-18} \mathrm{~m}^{2}, 201.55 \times 10^{-18} \mathrm{~m}^{2}$, and $387.61 \times 10^{-18} \mathrm{~m}^{2}$ considering no hydration and hydrated 2 days, 5 days, and 10 days, 
showing that the permeability considering hydrated 10 days is 13.1 times of no hydration, which concludes that greater fractures are generated for this kind of shale with more days of hydration under the same condition.

Therefore, the curves of permeability variation can be summarized into that more hydrated days cause much more pores and fractures to enlarge larger seepage channels, and the water is speeded up to flow in the cracks resulting in corresponding permeability of shales with more hydrated days which increases more obviously under the above same load combination. The main reason for the hydration enlarging the crack aperture and quantities is crack propagating and new cracks initiating among the inorganic minerals, and the crack widening between the banded organic materials and inorganic minerals. And also, the ion such as $\mathrm{Na}^{+}, \mathrm{K}^{+}$, and $\mathrm{Ca}^{2+}$ will be dissolved; once the water is drained out, the ion will gather on the clay surface causing the wider crack. Therefore, the crack should be connected to form larger cracks, and corresponding permeability will increase greatly.

3.2. Permeability Characteristics of Hydrated Shale Induced. To comprehensively characterize the permeability change of reservoir rocks, an important index named damage variable $D$ describing the defect variation closely related to the microcrack growth and microstructural evolution was proposed. Based on the research in the literature [16], it is assumed that the strength of rock microelements obeys Weibull stochastic distribution; accordingly, the damage variable $D$ can be described by

$$
D=1-\exp \left[-\left(\frac{F}{F_{0}}\right)^{m}\right]
$$

where $m$ and $F_{0}$ are the Weibull parameters and $F$ is the random strength variables of rock microelements.

Suppose $F=f\left(\tilde{\sigma}^{\prime}\right)$, where $\tilde{\sigma}^{\prime}$ is the effective stress tensors, so the rock failure criteria can be written by

$$
F=f\left(\tilde{\sigma^{\prime}}\right)-k_{0}=0
$$

where $k_{0}$ is constant related to cohesion and friction angle considering the rock yielding; $F=f\left(\widetilde{\sigma^{\prime}}\right) \geq k_{0}$ represents the rock yielding or failing. And the rock failure criteria may be described based on Drucker-Prager criteria

$$
\begin{aligned}
& F=\alpha{\widetilde{I^{\prime}}}_{1}+\sqrt{{\tilde{J^{\prime}}}_{2},} \\
& \alpha=\frac{\sin \varphi}{\sqrt{9+3 \sin ^{2} \varphi}},
\end{aligned}
$$

where $\phi$ is the friction angle; $\tilde{I}_{1}^{\prime}$ is first invariant of effective stress tensor, and $\tilde{J}_{2}^{\prime}$ is the second invariant of effective stress tensor.
Suppose the stress-strain of rocks obeys the Generalized Hook's Law, the principle stress-stain can be written by

$$
\tilde{\varepsilon}_{1}^{\prime}=\frac{1}{E}\left[\tilde{\sigma}_{1}^{\prime}-\mu\left(\tilde{\sigma}_{2}^{\prime}+\tilde{\sigma}_{3}^{\prime}\right)\right]
$$

where $E$ is the elastic module and $\mu$ is Poisson's ratio.

Considering $\sigma_{1}>\sigma_{2}=\sigma_{3}$ in triaxial tests and $\varepsilon_{1}=\tilde{\varepsilon}^{\prime}{ }_{1}$, substituting the expression $\tilde{\sigma}_{i j}^{\prime}=\left(\sigma_{i j}-p_{w} \delta\right)_{i j} /(1-D)$ into Equation (6) gives

$$
\sigma_{1}=E \varepsilon_{1}(1-D)+2 \mu \sigma_{3}+(1-2 \mu) p_{w}
$$

And also, the measured axial deviatoric stress $\sigma_{1 t}$ and real axial stain $\varepsilon_{1}$ should be shown in Equation (8) and Equation (9).

$$
\begin{gathered}
\sigma_{1 t}=\sigma_{1}-\sigma_{3} \\
\varepsilon_{1}=\varepsilon_{1 t}+\varepsilon_{10}
\end{gathered}
$$

Therefore, the statistical damage constitutive model [16] considering pore pressure can be written by

$$
\begin{gathered}
\sigma_{1 t}=\left[E \varepsilon_{1 t}+(1-2 \mu)\left(\sigma_{3}-p_{w}\right)\right] \exp \left[-\left(\frac{F}{F_{0}}\right)^{m}\right]+(2 \mu-1)\left(\sigma_{3}-p_{w}\right) \\
F=\frac{\left[E \varepsilon_{1 t}+(1-2 \mu)\left(\sigma_{3}-p_{w}\right)\right]}{\sigma_{1 t}+(1-2 \mu)\left(\sigma_{3}-p_{w}\right)} \cdot\left[\frac{\sin \varphi\left(\sigma_{1 t}+3 \sigma_{3}-3 p_{w}\right)}{\left.\sqrt{9+3 \sin ^{2} \varphi}+\frac{\sigma_{1 t}}{\sqrt{3}}\right]}\right. \\
\frac{\sigma_{1 t}-(2 \mu-1)\left(\sigma_{3}-P_{w}\right)}{E \varepsilon_{1 t}+(1-2 \mu)\left(\sigma_{3}-P_{w}\right)}=\exp \left(-\left(\frac{F}{F_{0}}\right)^{m}\right)
\end{gathered}
$$

where $E$ is elastic module, $\varepsilon_{1 t}$ is deviatoric strain; $\sigma_{1 t}$ is deviatoric stress, $\sigma_{3}$ is confining pressure, $p_{w}$ is permeable pressure, $\varphi$ is internal frictional angle, and $\mu$ is Poisson's ratio.

And then, Equation (5) may be changed as below:

$$
\begin{aligned}
& \frac{\sigma_{1 t}-(2 \mu-1)\left(\sigma_{3}-P_{w}\right)}{E \varepsilon_{1 t}+(1-2 \mu)\left(\sigma_{3}-P_{w}\right)}=\exp \left(-\left(\frac{F}{F_{0}}\right)^{m}\right), \\
& \ln \left\{\ln \left[\frac{\sigma_{1 t}-(2 \mu-1)\left(\sigma_{3}-P_{w}\right)}{E \varepsilon_{1 t}+(1-2 \mu)\left(\sigma_{3}-P_{w}\right)}\right]\right\}=m \ln F-B, \\
& Y=m X-B,
\end{aligned}
$$

in which, $X=\ln F ; \quad Y=\ln \left\{\ln \left[\left(E \varepsilon_{1 t}+(1-2 \mu)\left(\sigma_{3}-p_{w}\right)\right) /\right.\right.$ $\left.\left.\left(\sigma_{1 t}+(1-2 \mu)\left(\sigma_{3}-p_{w}\right)\right)\right]\right\} ; \quad B$ is the fitting parameter; and $F_{0}$ can be calculated by $F_{0}=\exp (\mathrm{B} / \mathrm{m})$ according to the fitting analysis.

Based on above derived formula, the curves of shale damage and strain and permeability and strain can be calculated and are shown in Figures 4(a)-4(c). The comparison of the permeability and corresponding damage variation about the shales with different hydrated days present similar variations. However, it was observed from Figure 4 that shale with hydration of 10 days has greater damage and larger permeability with the same strain, indicating that more fractures and cracks representing greater damage have generated for this shale with more days of hydration. As for the shale 


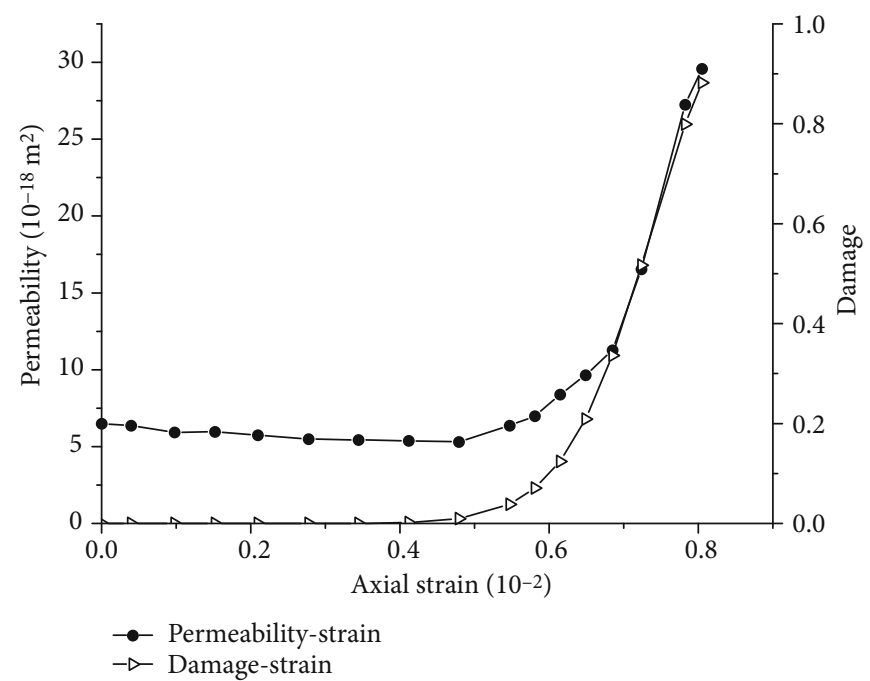

(a)

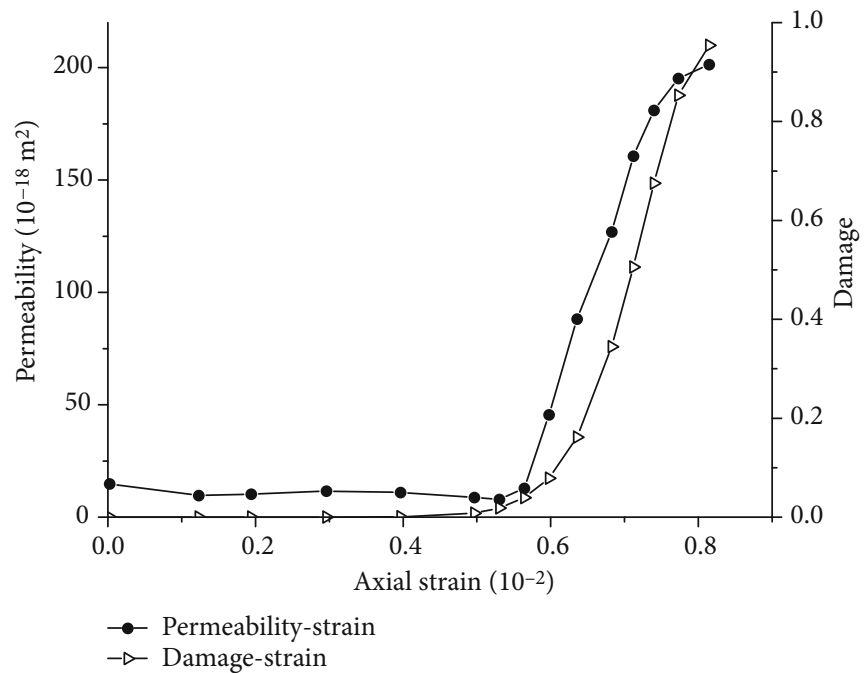

(b)

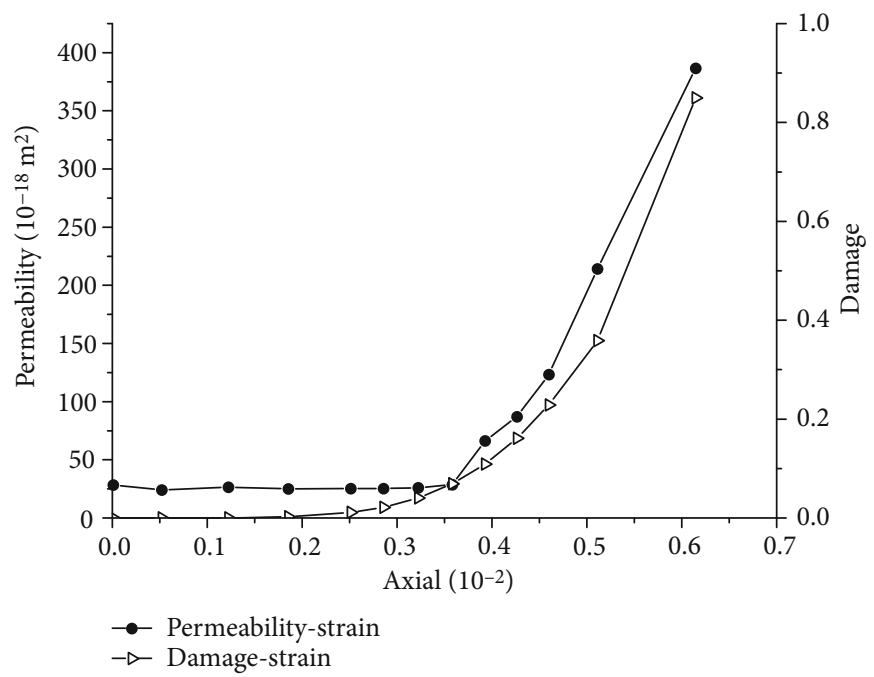

(c)

FIgURE 4: The permeability and damage coefficient of the shale rocks vs. axial strain considering hydrated days. The labels in Fig.4 are as follows,(a) 2 days (b) 5 days (c) 10 days. 
samples with the same hydrated days, it can be seen that the variation patterns of the damage and permeability variation are similar to the deviatoric stress variation in Figure 3, indicating that increasing loads enlarge the shale damage and permeability, so the damage variation rate can be considered to describe the crack propagation and permeability development.

Therefore, the permeability related to the damage variable $D$ can be written by Equation (12) using the testing data of hydrated 2 days, 5 days, and 10 days, shown in Figures 5(a)-5(c). It can be seen from the fitting curves that the relationship of the permeability and corresponding damage variable can be expressed by exponential functions with the correlation coefficient exceeding 0.97 , indicating that the gradual damage is the key to describe the permeability evolution.

$$
k=\zeta \exp \left(a+b D+c D^{2}\right)
$$

where $k$ is the permeability, $D$ is damage variable, $\zeta$ is a parameter valued $10^{-18}$, and $a, b, c$ are fitting parameters based on the experimental data.

And also, it can be observed that the shale permeability increases with greater damage variable, indicating that the shale damage variation can represent inner crack propagation, and the permeability evolution is closely related to the crack propagation, so the permeability evolution is considered to be synchronized with the damage evolution. In addition, the curves $k \sim D$ in Figures 5(a)-5(c) show that the shale permeability in Figure 5(c) with 10-day hydrated days is the greatest under the same loading conditions compared with other shales with less hydrated days; the main reason is concluded that initial damage is the greatest for 10-day hydrated shales resulting in the greatest initial permeability and it was kept the greatest even with the same damage variable, explaining the effect of hydration on the shale permeability.

\section{The Permeability of the Shale under Loading and Unloading Conditions}

\subsection{The Permeability Variation under the First Loading and Unloading Conditions}

4.1.1. The Permeability Variation under the First Loading Conditions. It can be observed from the black solid lines in Figures 6(a)-6(d) that the permeability variation decreased sharply with increasing confining pressure in the initial loading stage; however, the value decreased smoothly with greater confining pressure. The reason is that the shale bedding with initial confining pressure may be closed and caused larger deformation, so the fracture aperture closed much more and formed less seepage channel to show smaller permeability. While the confining pressure was increased significantly, the pores and fractures cannot be compacted more easily, and the permeability changes very slowly. Therefore, the confining pressure dominated the permeability variation considering the same seepage pressure. As seen from the solid black lines in Figures 6(a)-6(d) considering the confining pressure increasing from $5 \mathrm{MPa}$ to $11 \mathrm{MPa}$, the shale permeability with no hydration and hydrated 2 days, 5 days and 10 days decrease from $6.2 \times 10^{-18} \mathrm{~m}^{2}, 8.58 \times 10^{-18} \mathrm{~m}^{2}, 14.88 \times$ $10^{-18} \mathrm{~m}^{2}$, and $24.45 \times 10^{-18} \mathrm{~m}^{2}$ to $0.58 \times 10^{-18} \mathrm{~m}^{2}, 0.77 \times$ $10^{-18} \mathrm{~m}^{2}, \quad 1.127 \times 10^{-18} \mathrm{~m}^{2}$, and $1.49 \times 10^{-18} \mathrm{~m}^{2}$. The changes for the shale permeability indicate that the permeability considering larger confining pressure is not sensitive to the load increment.

Therefore, considering the same seepage pressure and axial pressure, the shale permeability decreased more smoothly with increasing confining pressure. In addition, the relationship of the permeability and confining pressure can be fitted as power function, exponential function, and quadratic polynomial function for the first loading conditions listed in Table 3 [22], and it can be seen that the fitting curves under the first loading condition based on the above testing data can be expressed by an exponential function with relation coefficient of 0.97 , showing that corresponding fitting coefficients of shales considering more hydrated days are greater.

4.1.2. The Permeability Variation under the First Unloading Conditions. It can be seen from the dotted lines in Figures 6(a)-6(d) that the permeability variation in the initial unloading stage increased more smoothly with confining pressure decreasing; however, the permeability increased relatively more sharply with smaller confining pressure. And also, when considering the confining pressure decreases from $11 \mathrm{MPa}$ to $5 \mathrm{MPa}$, the shale permeability of no hydration and hydrated 2 days, 5 days, and 10 days increases from $0.42 \times 10^{-18} \mathrm{~m}^{2}, 0.61 \times 10^{-18} \mathrm{~m}^{2}, 0.70 \times 10^{-18} \mathrm{~m}^{2}$, and $1.12 \times 10^{-18} \mathrm{~m}^{2}$ to $1.54 \times 10^{-18} \mathrm{~m}^{2}, 1.38 \times 10^{-18} \mathrm{~m}^{2}, 2.5 \times$ $10^{-18} \mathrm{~m}^{2}$, and $4.90 \times 10^{-18} \mathrm{~m}^{2}$. It can be concluded that considering the same seepage pressure and axial pressure, the shale permeability increases much more with decreasing confining pressure. In addition, the fitting curves under the unloading condition based on the above testing data can be expressed by an exponential function with relation coefficient of 0.95 listed in Table 3.

Therefore, as observed from the figures and tables about the permeability variations under the first loading and unloading conditions, it can be seen that the permeability under the same confining pressure in the loading stage is larger than that in the unloading stage, especially that the permeability cannot recover to the original value even if the confining pressure reaches to the origin condition. For example, the permeability of the shale with 2-day hydration is $8.6 \times 10^{-18} \mathrm{~m}^{2}$ with confining pressure $11 \mathrm{MPa}$ in the loading stage, otherwise the permeability is $1.4 \times$ $10^{-18} \mathrm{~m}^{2}$ in the unloading stage even if the confining pressure is unloaded to the original value, and the permeability just recovers to $20 \%$ of the original value. The main reason is that loading process generates irreversible damage inside the shales and cannot recover again in the unloading process. Thus, the curves of shale permeability cannot coincide in the loading and unloading stage. 


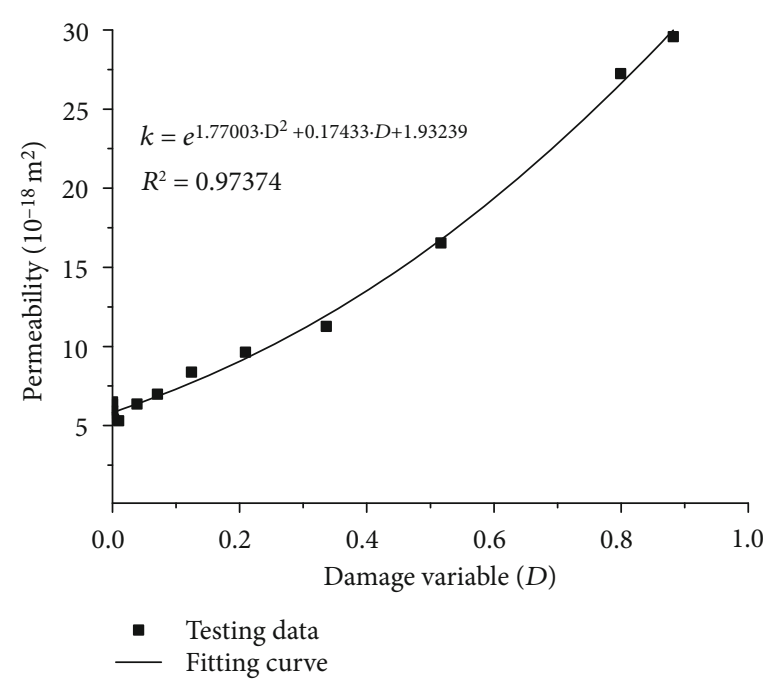

(a)

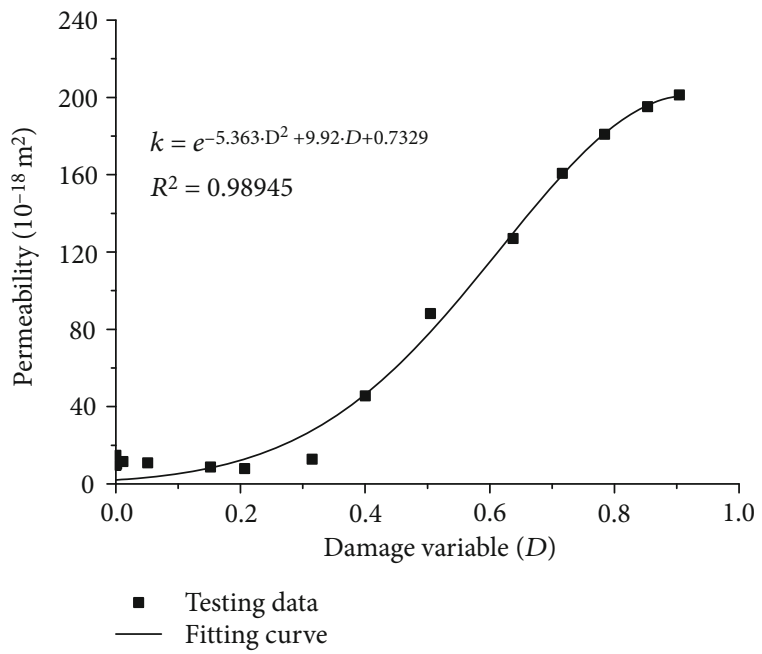

(b)

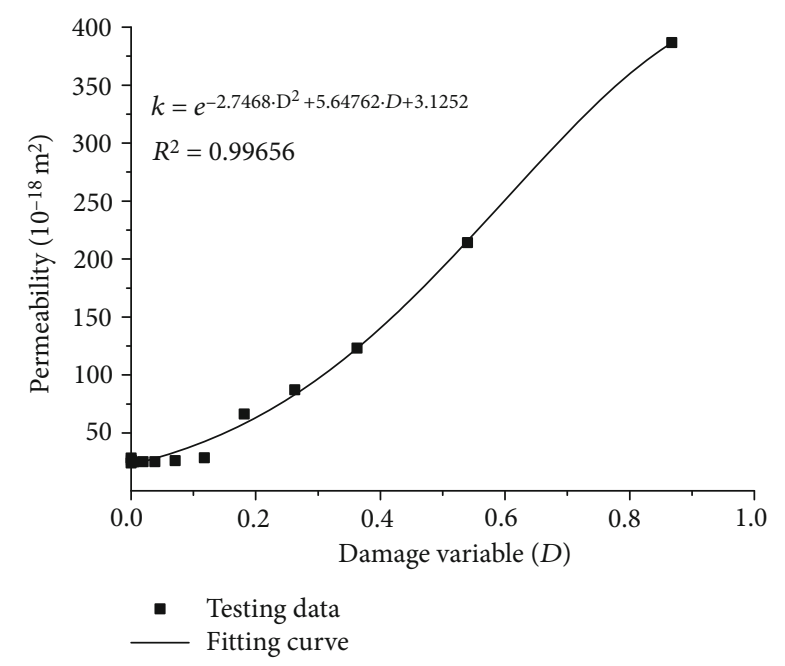

(c)

FIGURE 5: The relationship of the permeability and damage variation considering hydrated days. The labels in Fig.5 are as follows,(a) 2 days (b) 5 days (c) 10 days.

4.2. The Permeability Variation under Cyclic Loading and Unloading Conditions. In order to describe the permeability evolution under cyclic loading and unloading conditions, the curves considering five cycles shown in Figures 6(a)-6(d) have been compared in detail. The comparisons indicate that the variation patterns of the shale permeability are similar to the variation considering the first loading and unloading conditions. And it can be clearly seen from the curves in Figure 6(a) (2) representing the magnified four cycles that considering the confining pressure increasing from $5 \mathrm{MPa}$ to $11 \mathrm{MPa}$ in the second cyclic loading and unloading process, the shale permeability with no hydration and hydrated 2 days, 5 days, and 10 days decreases from $1.54 \times 10^{-18} \mathrm{~m}^{2}, 1.39 \times 10^{-18} \mathrm{~m}^{2}, 2.5 \times 10^{-18}$ $\mathrm{m}^{2}$, and $4.9 \times 10^{-18} \mathrm{~m}^{2}$ to $0.28 \times 10^{-18} \mathrm{~m}^{2}, 0.25 \times 10^{-18} \mathrm{~m}^{2}$, $0.69 \times 10^{-18} \mathrm{~m}^{2}$, and $0.4 \times 10^{-18} \mathrm{~m}^{2}$. And also, when considering the confining pressure decreases from $11 \mathrm{MPa}$ to $5 \mathrm{MPa}$, the shale permeability of no hydration and hydrated 2 days, 5 days, and 10 days increases from $0.21 \times 10^{-18} \mathrm{~m}^{2}, 0.25$ $\times 10^{-18} \mathrm{~m}^{2}, \quad 0.69 \times 10^{-18} \mathrm{~m}^{2}$, and $0.4 \times 10^{-18} \mathrm{~m}^{2}$ to $0.7 \times$ $10^{-18} \mathrm{~m}^{2}, \quad 0.82 \times 10^{-18} \mathrm{~m}^{2}, \quad 1.74 \times 10^{-18} \mathrm{~m}^{2}, \quad$ and $2.58 \times$ $10^{-18} \mathrm{~m}^{2}$.

Also, as seen from the curves in Figure 6(b) (2) considering the confining pressure increasing from $5 \mathrm{MPa}$ to $11 \mathrm{MPa}$ in the third cyclic loading and unloading process, the shale permeability with no hydration, hydrated 2 days, 5 days and 10 days decreases from $0.7 \times 10^{-18} \mathrm{~m}^{2}, 0.82 \times 10^{-18} \mathrm{~m}^{2}$, $1.74 \times 10^{-18} \mathrm{~m}^{2}$, and $2.58 \times 10^{-18} \mathrm{~m}^{2}$ to $0.18 \times 10^{-18} \mathrm{~m}^{2}$, $0.56 \times 10^{-18} \mathrm{~m}^{2}, 0.45 \times 10^{-18} \mathrm{~m}^{2}$, and $0.31 \times 10^{-18} \mathrm{~m}^{2}$. And also, when considering the confining pressure decreases from $11 \mathrm{MPa}$ to $5 \mathrm{MPa}$, the shale permeability of no hydration and hydrated 2 days, 5 days, and 10 days increases from $0.18 \times 10^{-18} \mathrm{~m}^{2}, 0.16 \times 10^{-18} \mathrm{~m}^{2}, 0.27 \times 10^{-18} \mathrm{~m}^{2}$ and $0.31 \times 10^{-18} \mathrm{~m}^{2}$ to $0.54 \times 10^{-18} \mathrm{~m}^{2}, 0.61 \times 10^{-18} \mathrm{~m}^{2}, 1.25 \times 10^{-18}$ $\mathrm{m}^{2}$ and $1.74 \times 10^{-18} \mathrm{~m}^{2}$.

And it is observed from the curves in Figure 6(c) (2) considering the confining pressure increasing from $5 \mathrm{MPa}$ to 

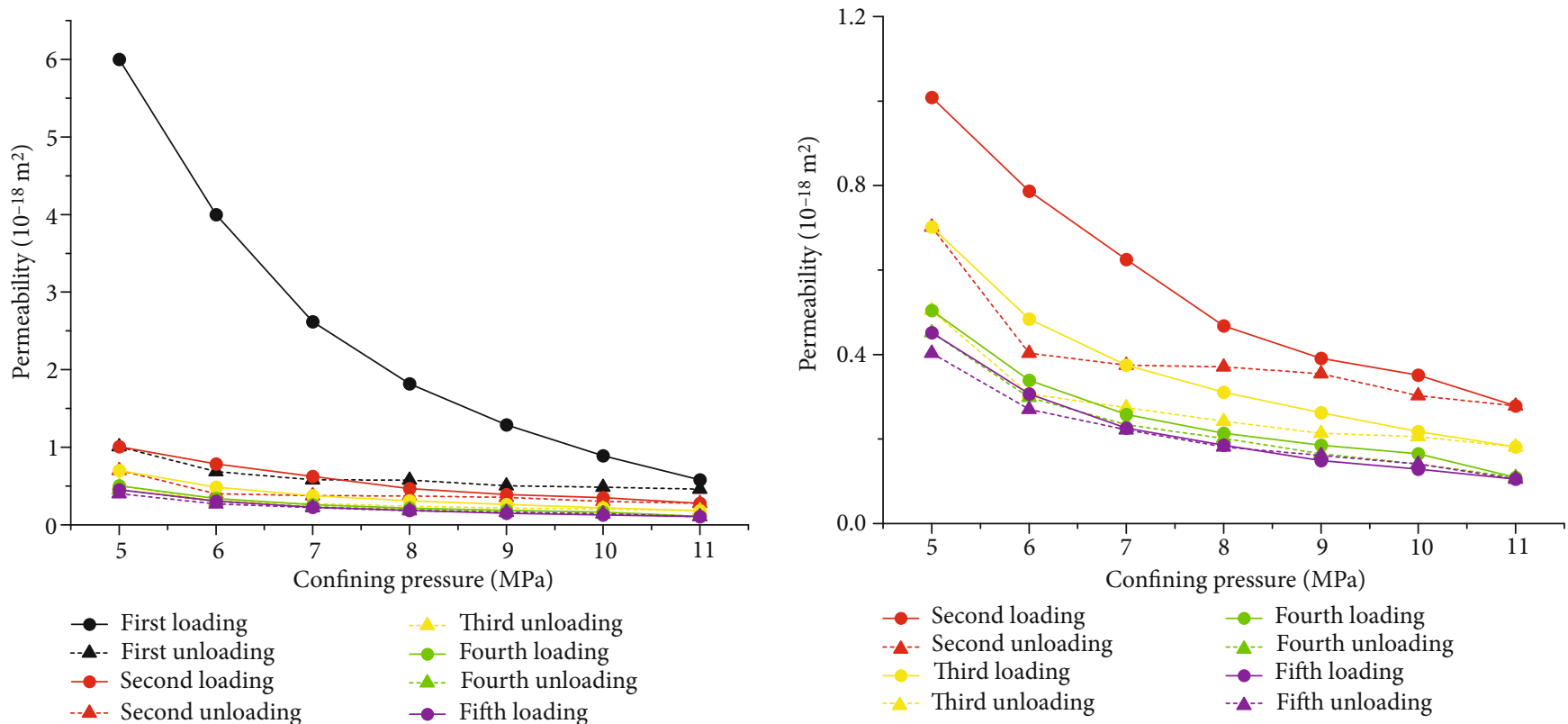

(a)
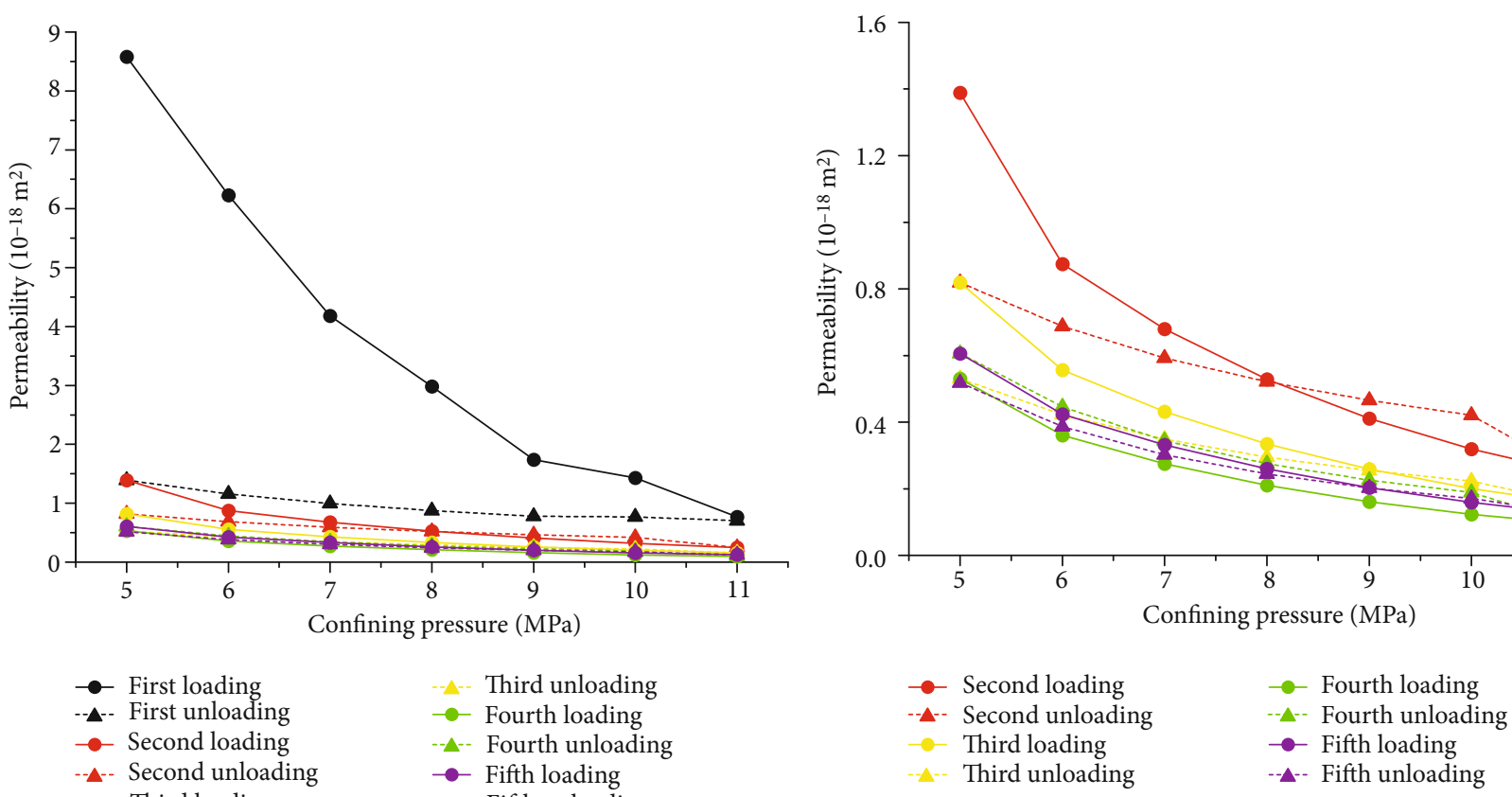

(b)

Figure 6: Continued. 

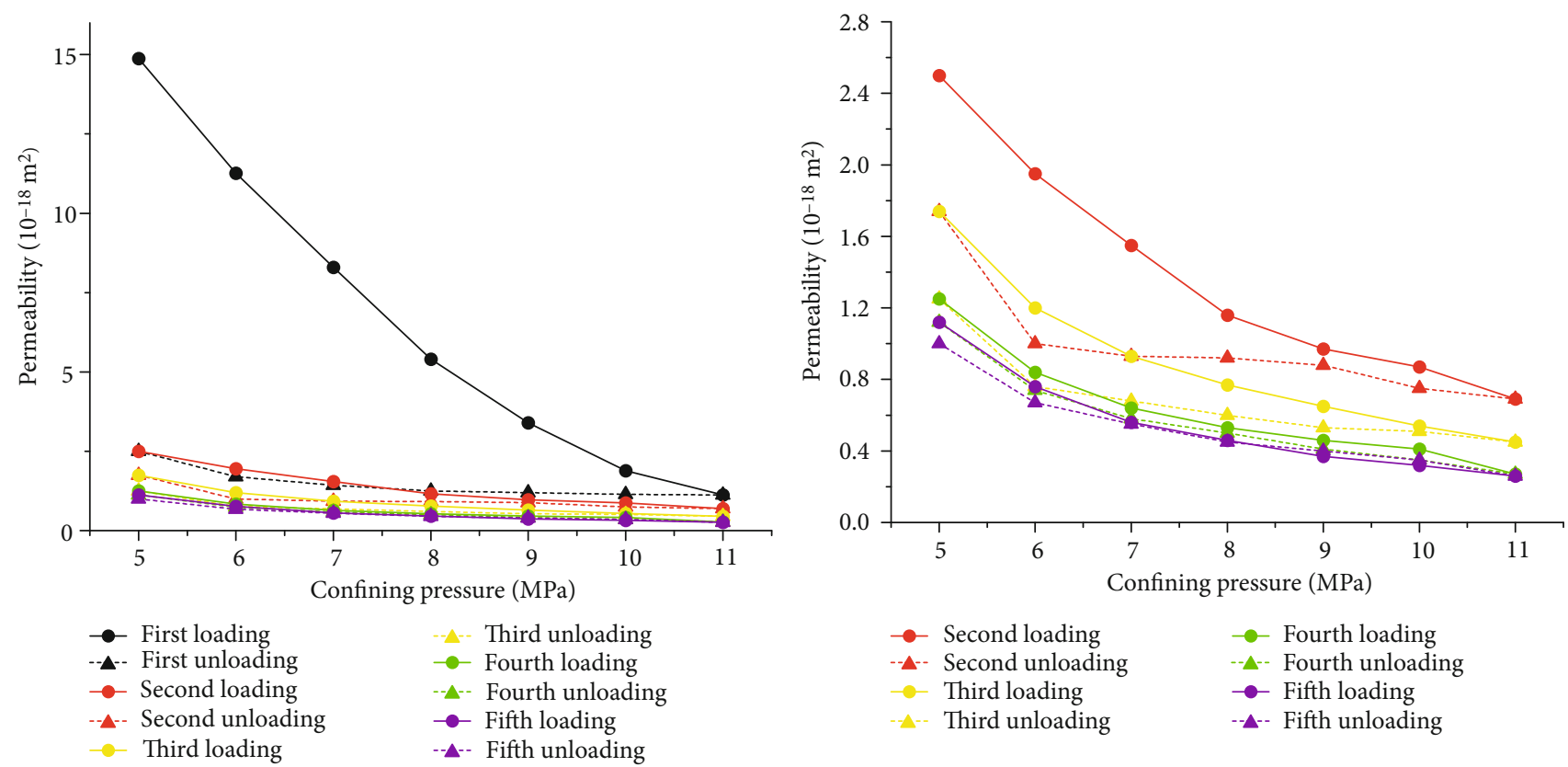

(c)
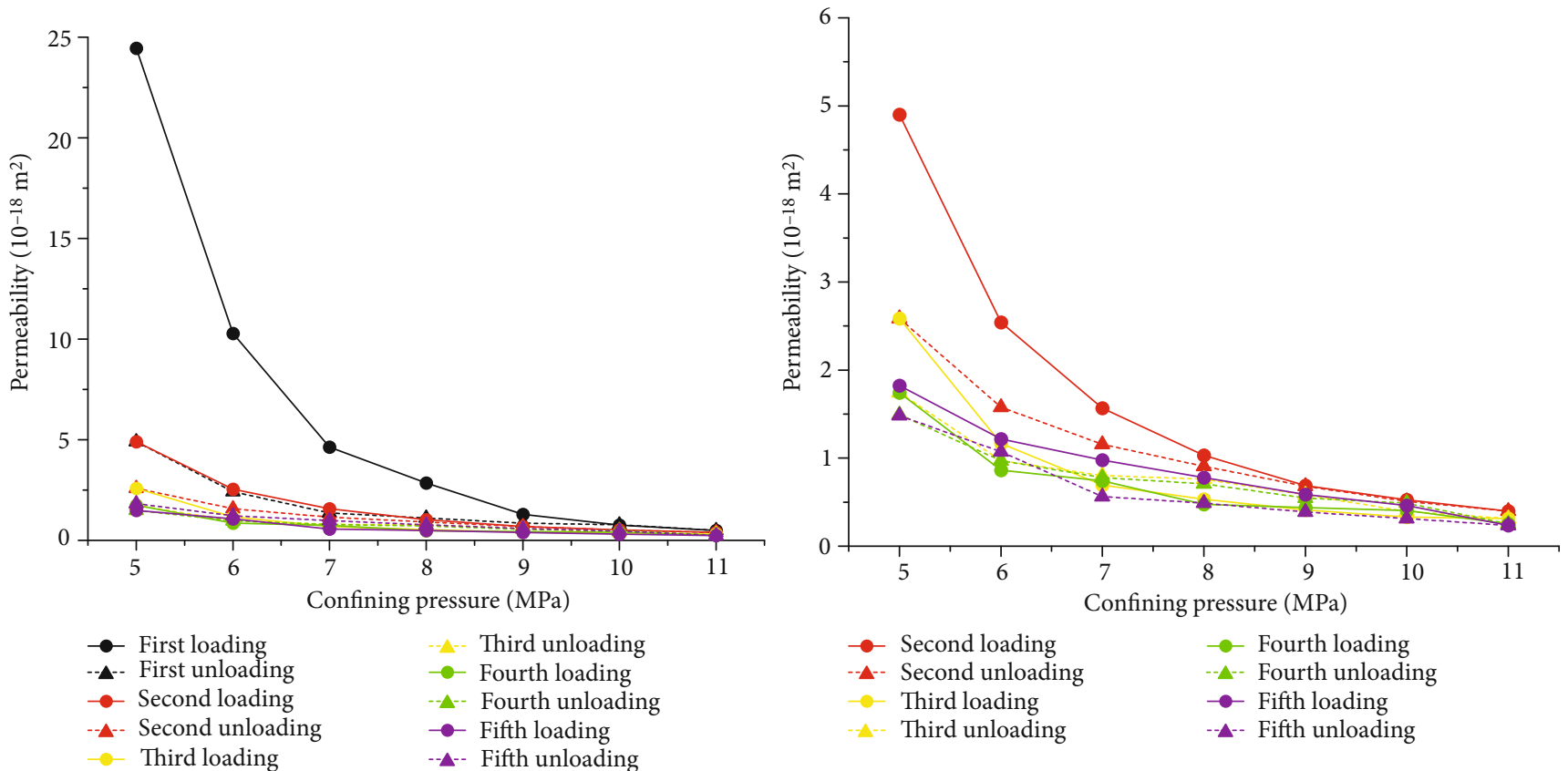

(d)

Figure 6: The permeability variation of the hydrated shale considering cycling loading and unloading conditions. The labels in Fig.6 are as follws, (a) No hydration (b) 2days (c) 5 days (d) 10 days.

$11 \mathrm{MPa}$ in the fourth cyclic loading and unloading process, the shale permeability with no hydration and hydrated 2 days, 5 days, and 10 days decreases from $0.51 \times 10^{-18} \mathrm{~m}^{2}$, $0.61 \times 10^{-18} \mathrm{~m}^{2}, 1.25 \times 10^{-18} \mathrm{~m}^{2}$, and $1.74 \times 10^{-18} \mathrm{~m}^{2}$ to $0.11 \times 10^{-18} \mathrm{~m}^{2}, 0.09 \times 10^{-18} \mathrm{~m}^{2}, 0.27 \times 10^{-18} \mathrm{~m}^{2}$, and 0.25 $\times 10^{-18} \mathrm{~m}^{2}$. And also, when considering the confining pressure decreases from $11 \mathrm{MPa}$ to $5 \mathrm{MPa}$, the shale permeability of no hydration and hydrated 2 days, 5 days, and 10 days increases from $0.11 \times 10^{-18} \mathrm{~m}^{2}, 0.12 \times 10^{-18} \mathrm{~m}^{2}, \quad 0.45 \times$
$10^{-18} \mathrm{~m}^{2}$, and $0.25 \times 10^{-18} \mathrm{~m}^{2}$ to $0.45 \times 10^{-18} \mathrm{~m}^{2}, 0.53 \times$ $10^{-18} \mathrm{~m}^{2}, 1.12 \times 10^{-18} \mathrm{~m}^{2}$, and $1.49 \times 10^{-18} \mathrm{~m}^{2}$.

Furthermore, as seen from the curves in Figures 6(d) (2) representing the magnified four cycles considering the confining pressure increasing from $5 \mathrm{MPa}$ to $11 \mathrm{MPa}$ in the fifth cyclic loading and unloading process, the shale permeability with no hydration and hydrated 2 days, 5 days, and 10 days decreases from $0.46 \times 10^{-18} \mathrm{~m}^{2}, 0.53 \times 10^{-18} \mathrm{~m}^{2}, 1.1 \times 10^{-18} \mathrm{~m}^{2}$, and $1.5 \times 10^{-18} \mathrm{~m}^{2}$ to $0.10 \times 10^{-18} \mathrm{~m}^{2}, 0.12 \times 10^{-18} \mathrm{~m}^{2}, 0.26 \times$ 
TABLE 3: Curves of permeability and confined pressure of hydrated shale rocks.

\begin{tabular}{|c|c|c|c|c|c|c|c|}
\hline Hydrated days & Cycles & $F_{S}$ & $\begin{array}{c}\text { Loading } \\
\text { Fitting curves }(y \text { represents } \\
\text { permeability } k ; x \text { represents } \\
\left.\text { confining pressure } P_{c}\right)\end{array}$ & $\begin{array}{c}\text { Relation } \\
\text { coefficient } R^{2}\end{array}$ & $F_{m}$ & $\begin{array}{c}\text { Unloading } \\
\text { Fitting curves }(y \text { represents } \\
\text { permeability } k ; x \text { represents } \\
\left.\text { confining pressure } P_{c}\right)\end{array}$ & $\begin{array}{c}\text { Relation } \\
\text { coefficient } R^{2}\end{array}$ \\
\hline \multirow{5}{*}{0} & 1 & 0.9 & $y=47.667 \exp (-0.41 x)$ & 0.99 & 0.181 & $y=4.163 x^{(-0.97)}$ & 0.99 \\
\hline & 2 & 0.21 & $y=2.95 \exp (-0.212 x)$ & 0.98 & 0.089 & $y=2.735 x^{(-0.962)}$ & 0.98 \\
\hline & 3 & 0.08 & $y=9.74 x^{(-1.657)}$ & 0.97 & 0.065 & $y=2.792 x^{(-1.16)}$ & 0.97 \\
\hline & 4 & 0.065 & $y=8.073 x^{(-1.744)}$ & 0.98 & 0.054 & $y=6.448 x^{(-1.681)}$ & 0.98 \\
\hline & 5 & 0.057 & $y=7.882 x^{(-1.802)}$ & 0.99 & 0.051 & $y=4.6972 x^{(-1.556)}$ & 0.99 \\
\hline \multirow{5}{*}{2} & 1 & 0.91 & $y=55.492 \exp (-0.370 x)$ & 0.99 & 0.092 & $y=4.163 x^{(-0.97)}$ & 0.99 \\
\hline & 2 & 0.13 & $y=40.556 x^{(-2.107)}$ & 0.98 & 0.071 & $y=2.735 x^{(-0.962)}$ & 0.98 \\
\hline & 3 & 0.07 & $y=22.95 x^{(-2.058)}$ & 0.97 & 0.059 & $y=2.792 x^{(-1.16)}$ & 0.97 \\
\hline & 4 & 0.056 & $y=17.271 x^{(-2.145)}$ & 0.98 & 0.046 & $y=6.448 x^{(-1.681)}$ & 0.98 \\
\hline & 5 & 0.05 & $y=13.697 x^{(-1.965)}$ & 0.99 & 0.044 & $y=4.6972 x^{(-1.556)}$ & 0.99 \\
\hline \multirow{5}{*}{5} & 1 & 0.924 & $y=92.738 \exp (-0.359 x)$ & 0.99 & 0.074 & $y=10.181 x^{(-0.962)}$ & 0.9 \\
\hline & 2 & 0.121 & $y=35.39 x^{(-1.629)}$ & 0.98 & 0.071 & $y=6.78 x^{(-0.962)}$ & 0.95 \\
\hline & 3 & 0.086 & $y=24.145 x^{(-1.657)}$ & 0.97 & 0.057 & $y=6.92 x^{(-1.159)}$ & 0.97 \\
\hline & 4 & 0.066 & $y=20.014 x^{(-1.744)}$ & 0.98 & 0.054 & $y=15.988 x^{(-1.681)}$ & 0.98 \\
\hline & 5 & 0.056 & $y=19.543 x^{(-1.802)}$ & 0.99 & 0.05 & $y^{=11.646 x(-1.556)}$ & 0.99 \\
\hline \multirow{5}{*}{10} & 1 & 0.95 & $y=1397.26 \exp (-0.811 x)$ & 0.99 & 0.072 & $y=316.21 x^{(-2.691)}$ & 0.99 \\
\hline & 2 & 0.18 & $y=775.56 x^{(-3.177)}$ & 0.98 & 0.067 & $y=103.7 x^{(-2.305)}$ & 0.98 \\
\hline & 3 & 0.092 & $y=141.97 x^{(-2.634)}$ & 0.97 & 0.056 & $y=39.639 x^{(-1.979)}$ & 0.97 \\
\hline & 4 & 0.061 & $y=50.236 x^{(-2.176)}$ & 0.98 & 0.043 & $y=32.695 x^{(-1.908)}$ & 0.98 \\
\hline & 5 & 0.051 & $y=60.482 x^{(-2.311)}$ & 0.99 & 0.042 & $y=81.857 x^{(-2.309)}$ & 0.99 \\
\hline
\end{tabular}

$10^{-18} \mathrm{~m}^{2}$, and $0.24 \times 10^{-18} \mathrm{~m}^{2}$. And also, when considering the confining pressure decreases from $11 \mathrm{MPa}$ to $5 \mathrm{MPa}$, the shale permeability of no hydration and hydrated 2 days, 5 days, and 10 days increases from $0.10 \times 10^{-18} \mathrm{~m}^{2}, 0.09 \times 10^{-18} \mathrm{~m}^{2}$, $0.26 \times 10^{-18} \mathrm{~m}^{2}$, and $0.24 \times 10^{-18} \mathrm{~m}^{2}$ to $0.40 \times 10^{-18} \mathrm{~m}^{2}, 0.52$ $\times 10^{-18} \mathrm{~m}^{2}, 1.0 \times 10^{-18} \mathrm{~m}^{2}$, and $1.42 \times 10^{-18} \mathrm{~m}^{2}$. However, it can be concluded from Figures 6(a) (2)-6(d) (2) that the variation rate of the shale permeability is more smooth after 3 cyclic loading and unloading processes, indicating that the shale permeability is mainly sensitive to the first load combination.

And also, the fitting curves of the shale permeability under 5 cyclic loading and unloading conditions are described by main power functions listed in Table 3. For deeply investigating the cyclic loading and unloading conditions influencing on the shale permeability variation, the permeability loss in the loading condition and permeability recovery in the unloading condition are introduced to describe the permeability evolution under complex conditions. The permeability based on the tests is normalized as

$$
F=\frac{k_{i}}{k_{0}} \times 100 \% \text {, }
$$

where $F$ is the dimensionless factor of the permeability, $k_{i}$ is the permeability under loading or unloading condition, and $k_{0}$ is the original permeability.

According to formula (13), the loss rate $F_{S}$ in the loading condition is defined as the ratio of the permeability in the beginning stage and permeability in the ending stage as $F_{S}=F_{0}-F_{t}$, in which $F_{0}$ is the dimensionless factor of the permeability in the beginning loading stage and $F_{t}$ is the dimensionless factor of the permeability in the ending loading stage. As for the unloading stage, the recovery is defined as $F_{m}=F_{C}-F_{t}$, where $F_{C}$ is the dimensionless factor of the permeability considering the confining pressure unloading to the original value. Based on the permeability under different load conditions, the loss rate and recovery rate are calculated and listed in Table 3. It can be seen from Table 3 that for the shale with no hydration, the permeability loss rate in the first cyclic condition is larger than $90 \%, 21 \%$ in the second cycle, $8 \%$ in the third cycle, $6.5 \%$ in the fourth cycle, and $5.7 \%$ in the fifth cycle. As for the shale specimens with hydration of 2 days, the permeability loss rate in the first cyclic condition is larger than $91 \%, 13 \%$ in the second cycle, $7.7 \%$ in the third cycle, $5.6 \%$ in the fourth cycle, and $5.0 \%$ in the fifth cycle. As for 


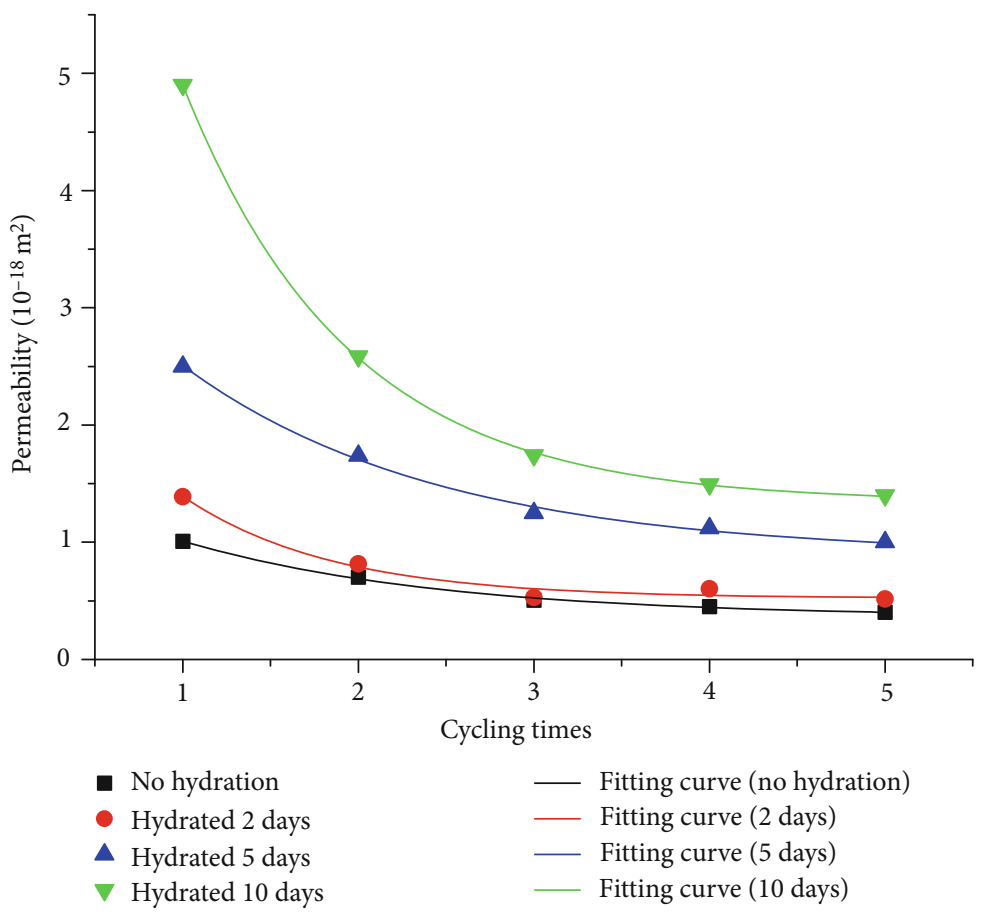

Figure 7: Comparison of permeability of hydrated shale under 5 cyclic loading and unloading conditions.

the shale with hydration of 5 days, the permeability loss rate in the first cyclic condition is larger than $92.4 \%, 12.1 \%$ in the second cycle, $8.6 \%$ in the third cycle, $6.6 \%$ in the fourth cycle, and $5.6 \%$ in the fifth cycle. As for the shale with hydration of 10 days, the permeability loss rate in the first cyclic condition is larger than $95.0 \%, 18.0 \%$ in the second cycle, $9.2 \%$ in the third cycle, $6.1 \%$ in the fourth cycle, and $5.1 \%$ in the fifth cycle. The permeability losses for different conditions indicate that the permeability loss rate decreases more smoothly considering more load cycles considering the same hydrated days. However, the hydrated days enlarge the permeability loss rate for the former three cycles, showing that the hydration effect cannot be ignored in the shale permeability research.

And also, the permeability in the unloading stage is smaller than that in the loading stage because of the irreversible deformation, so the permeability recovery listed in Table 3 is relatively smaller. The results indicate that for the shale with no hydration, the permeability recovery rate in the first cyclic condition is $18.1 \%, 8.9 \%$ in the second cycle, $6.5 \%$ in the third cycle, $5.4 \%$ in the fourth cycle, and $5.1 \%$ in the fifth cycle. As for the shale with hydration of 2 days, the permeability recovery rate in the cyclic condition is $9.2 \%, 7.1 \%$ in the second cycle, $5.9 \%$ in the third cycle, $4.6 \%$ in the fourth cycle, and $4.4 \%$ in the fifth cycle. As for the shales with hydration of 5 days, the permeability recovery rate in the cyclic condition is $7.4 \%, 7.1 \%$ in the second cycle, $5.7 \%$ in the third cycle, $5.4 \%$ in the fourth cycle, and $5.0 \%$ in the fifth cycle. As for the shale with hydration of 10 days, the permeability recovery rate in the cyclic condition is $7.2 \%, 6.7 \%$ in the second cycle, $5.6 \%$ in the third cycle, $4.3 \%$ in the fourth cycle, and $4.2 \%$ in the fifth cycle. The permeability recovery rate is less than $20 \%$ after the first unloading, indicating that the shale permeability with obvious irreversible deformation under loading condition is difficult to be recovered to the original value.

In addition, the comparison listed in Table 3 shows that the permeability loss rate and recovery rate is related to the hydration days, indicating that the loss rate is greater and the recovery rate is less with more hydration days, indicting the permeability in the loading stage is sensitive to the confining pressure, but insensitive to the confining pressure in the unloading condition. Thus, the permeability in the end of the every cycle is given by Figure 7, indicating that for the shale considering certain hydrated days, more cycles cause the permeability to change smoothly and reduce the sensibility of the permeability, and the permeability is greater with more hydrated days considering the same load combination, indicating permeability with more hydration is more sensitive to the cycles.

4.3. The Sensibility of the Shale Permeability on the Stress under Cyclic Loading and Unloading Conditions. For describing the relationship of the permeability and the confining pressure under cyclic loading and unloading conditions, the sensibility coefficient is defined to investigate the shale permeability variation. The larger coefficient indicates the permeability is more sensitive to the stress. According to references $[29,30]$, the sensibility coefficient $c_{k}$ can be written by formula (14), where $k_{0}$ is the initial permeability for different hydrated shale samples, and corresponding permeability is $6.63 \times 10^{-18} \mathrm{~m}^{2}, 8.69 \times 10^{-18} \mathrm{~m}^{2}, 14.65 \times 10^{-18} \mathrm{~m}^{2}$, and $26.58 \times 10^{-18} \mathrm{~m}^{2}$ for the shale with no hydration and hydrated 2 days, 5 days, and 10 days.

$$
c_{k}=-\frac{1}{k_{0}} \frac{\partial k}{\partial p} .
$$




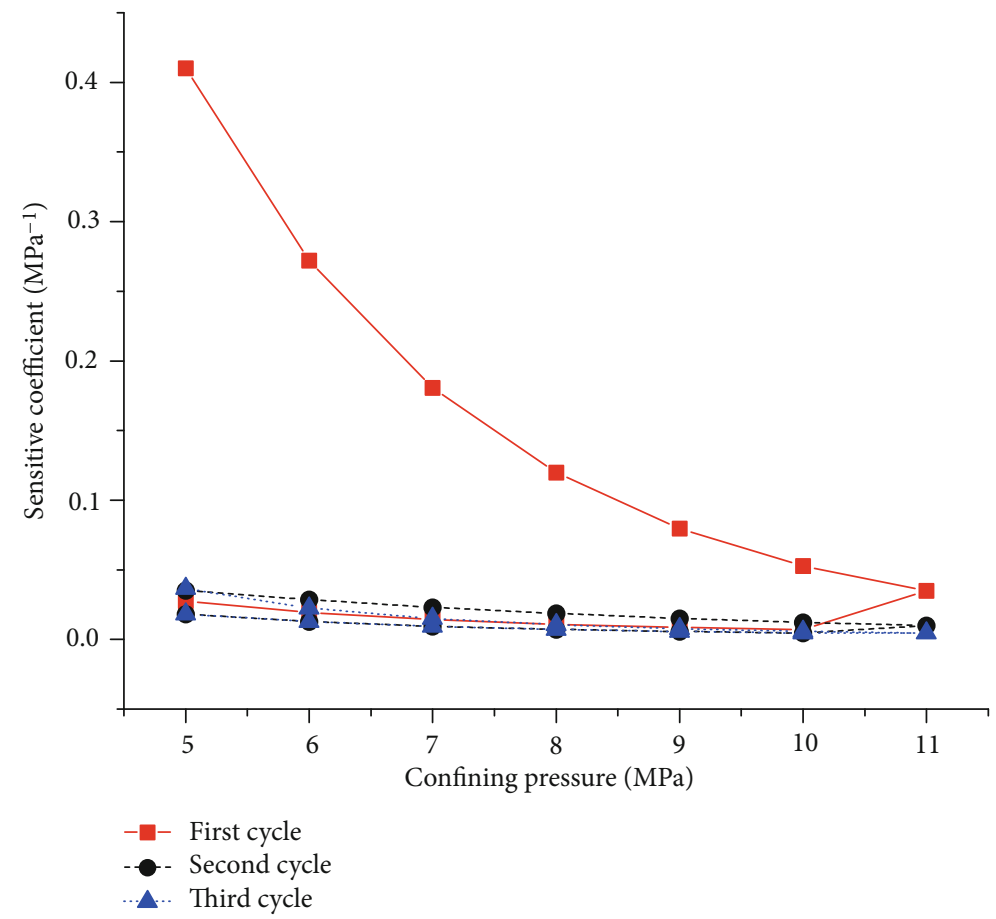

(a)

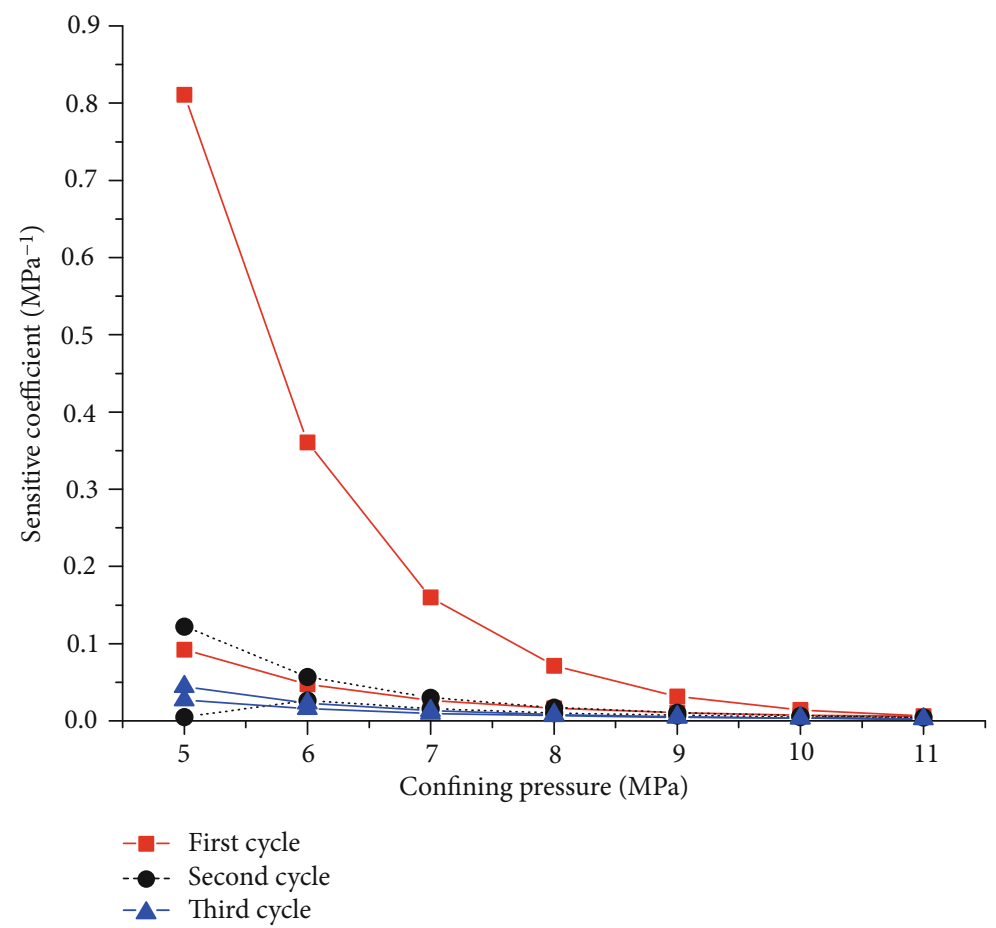

(b)

FIgure 8: Permeability-stress-sensitive coefficient of reservoir shale with different hydrated days. The labels in Fig.8 is as follows, (a) No hydration (b) 10 days.

Combined with the permeability expressions in Table 3, the sensibility coefficient $c_{k}$ can be calculated for the shale with no hydration and hydrated 10 days. And $c_{k}$ are compared using the testing data based on three cyclic loads to research on the sensibility variation. It can be observed from
Figure 8 that in the loading condition, $c_{k}$ decreases with increasing confining pressure, has a larger variation rate under lower confining pressure, shows stronger sensibility, and presents insensibility to the larger confining pressure, indicating that increasing confining pressure compresses 
the shale fractures and the same pressure increment cannot greatly change the permeability to reduce the sensibility. As for the unloading condition, $c_{k}$ may recover smoothly with decreasing confining pressure. It can be concluded that the irreversible deformation cannot recover to the original stag, and corresponding $c_{k}$ is smaller than that under the same confining pressure condition in the loading stage, which is in accordance with the variation of the permeability loss rate and recovery rate. Compared with the coefficient $c_{k}$ of the shale with no hydration and hydrated 10 days, $c_{k}$ in the latter condition is quiet larger, emphasizing the hydration effect on the shale damage and permeability.

\section{Conclusions}

The hydrated reservoir shale as a case study and the permeability evolution under cyclic loading and unloading conditions are researched using the experiments and theoretical analysis, and the corresponding permeability loss rate, recovery rate, and stress sensibility are deeply investigated to reveal the evolution mechanism of the shale permeability considering the hydration and cyclic loading and unloading conditions. The main conclusions are obtained as below:

(1) The curves of stress and strain have the same variation, and lower peak strength and greater permeability are obtained with more hydrated days. Then, the permeability evolution based on the damage theory shows that permeability is simultaneous to the damage variation, greater damage greater permeability

(2) In the primary loading stage, the shale permeability increases with more hydrated days and decreases with increasing confining pressure, indicating that larger confining pressure makes the shale pores and fractures more compacted to form less seepage channels. In the unloading stage, the permeability under the same confining pressure is smaller than that in the loading stage. And the curves of the permeability under loading and unloading conditions cannot coincide. As for 5 cyclic loading and unloading conditions, the relationship of the permeability and the confining pressure in the first loading stage is a negative exponent function and then the power functions, and in the unloading stage, the relationship is power function

(3) The permeability loss rate and the permeability recovery rate less than $20 \%$ decreases with more cyclic loading and unloading conditions. And the loss rate and recovery rate are very obvious in the first stage, indicating that both rates are sensitive to the first load combination

(4) The sensibility of the permeability and the stress indicates that in the loading stage, the permeability is more sensitive under smaller confining pressure, and increasing confining pressure reduces the sensibility, and in the unloading stage, the sensitive coeffi- cient is smaller than that under the same confining pressure in the loading stage, indicating the irreversible deformation cannot recover to the original condition, which is in accordance with the permeability loss rate and recovery rate

\section{Data Availability}

The data in this manuscript is based on the lab experiments and applicable.

\section{Conflicts of Interest}

The authors declare that there are no conflicts of interest regarding the publication of this paper.

\section{Acknowledgments}

The research is financially supported by the National Natural Science Foundation of China No. 51779021 and the Fundamental Research Funds for the Central Universities No. 2020CDCGJ021.

\section{References}

[1] H. Sone and M. D. Zoback, "Mechanical properties of shalegas reservoir rocks-part 1: static and dynamic elastic properties and anisotropy," Geophysics, vol. 78, pp. 381-392, 2013.

[2] J. P. Liu and J. S. Sun, "Borehole wall collapse and control in shale gas well drilling," Drilling Fluid and Completion Fluid, vol. 33, pp. 25-29, 2016.

[3] H. Xue, S. Zhou, Y. Jiang, F. Zhang, Z. Dong, and W. Guo, "Effects of hydration on the microstructure and physical properties of shale," Petroleum Exploration and Development, vol. 45, no. 6, pp. 1146-1153, 2018.

[4] B. Z. Shi and B. R. Xia, "The variation of microstructures in the hard brittle shale hydration process," Journal of Daqing Petroleum University, vol. 35, pp. 28-34, 2011.

[5] T. Ma and P. Chen, "Study of meso-damage characteristics of shale hydration based on CT scanning technology," Petroleum Exploration and Development, vol. 41, no. 2, pp. 249-256, 2014.

[6] X. Liu, W. Zeng, L. Liang, and J. Xiong, "Experimental study on hydration damage mechanism of shale from the Longmaxi Formation in southern Sichuan Basin, China," Petroleum, vol. 2, no. 1, pp. 54-60, 2016.

[7] L. Massat, O. Cuisinier, I. Bihannic et al., "Swelling pressure development and inter-aggregate porosity evolution upon hydration of a compacted swelling clay," Applied Clay Scencei, vol. 124-125, pp. 197-210, 2016.

[8] X. J. Liu, J. Xiong, and L. X. Liang, "Hydration experiment of hard brittle shale of the Longmaxi Formation," Journal of Southwest Petroleum University (Science and Technology Edition), vol. 38, pp. 178-186, 2016.

[9] S. Zhang and J. J. Sheng, "Study of the propagation of hydration-induced fractures in Mancos Shale using computerized tomography," International Journal of Rock Mechanics and Mining Sciences, vol. 95, pp. 1-7, 2017.

[10] H. W. Teng, S. Ren, and D. Y. Jiang, "Experimental study of mechanical properties of water-saturated weaken shale in 
Gonghe tunnel," Chinese Journal of Rock Mechanics and Engineering, vol. 29, Supplement 1, pp. 2657-2662, 2010.

[11] B. L. Zhu, X. N. Li, X. Y. Wu, and Y. J. Wang, "Experimental study of mechanical properties of water-saturated weaken shale," Chinese Journal of Rock Mechanics and Engineering, no. S2, pp. 3896-3905, 2015.

[12] H. Roshan, S. Ehsani, C. E. Marjo, M. S. Andersen, and R. I. Acworth, "Mechanisms of water adsorption into partially saturated fractured shales: an experimental study," Fuel, vol. 159, pp. 628-637, 2015.

[13] S. Zhang and J. J. Sheng, "Effect of water imbibition on hydration induced fracture and permeability of shale cores," Journal of Natural Gas Science and Engineering, vol. 45, pp. 726-737, 2017.

[14] X. Tan, H. Konietzky, and T. Frühwirt, "Laboratory observation and numerical simulation of permeability evolution during progressive failure of brittle rocks," International Journal of Rock Mechanics and Mining Sciences, vol. 68, pp. 167-176, 2014.

[15] T. Zhou, S. Zhang, L. Yang, X. Ma, Y. Zou, and H. Lin, "Experimental investigation on fracture surface strength softening induced by fracturing fluid imbibition and its impacts on flow conductivity in shale reservoirs," Journal of Natural Gas Science and Engineering, vol. 36, pp. 893-905, 2016.

[16] X. Liu, M. Xu, and K. Wang, "Mechanism of permeability evolution for reservoir sandstone with different physical properties," Geofluids, vol. 2018, Article ID 5327895, 16 pages, 2018.

[17] J. Yu, X. Chen, Y. Y. Cai, and H. Li, “Triaxial test research on mechanical properties and permeability of sandstone with a single joint filled with gypsum," KSCE Journal of Civil Engineering, vol. 20, no. 6, pp. 2243-2252, 2016.

[18] J. Yu, X. Chen, H. Li, J. W. Zhou, and Y. Y. Cai, "Effect of freeze-thaw cycles on mechanical properties and permeability of red sandstone under triaxial compression," Journal of Mountain Science, vol. 12, no. 1, pp. 218-231, 2015.

[19] G. Z. Yin, W. P. Li, M. H. Li, X. Li, B. Z. Deng, and C. B. Jiang, "Permeability properties and effective stress of raw coal under loading-unloading conditions," Journal of China Coal Society, vol. 39, no. 8, pp. 1497-1503, 2014.

[20] J. Xu, B. B. Li, T. Zhou, D. Liu, J. Cao, and G. B. Ye, "Experimental study of deformation and seepage characteristics of coal under cyclic loading," Chinese Journal of Rock Mechanics and Engineering, vol. 33, no. 2, pp. 225-234, 2014.

[21] R. K. Pan, Y. P. Cheng, J. Dong, and H.-D. Chen, "Research on permeability characteristics of layered natural coal under different loading and unloading," Journal of China Coal Society, vol. 39, no. 3, pp. 473-477, 2014.

[22] Q. Kong, H. L. Wang, and W. Y. Xu, "Experimental study on permeability and porosity evolution of sandstone under cyclic loading and unloading," Chinese Journal of Geotechnical Engineering, vol. 37, no. 10, pp. 1893-1900, 2015.

[23] Z. H. Zhang, Q. C. Sun, D. Z. Li, M. P. Du, and H. Y. Yao, "Experimental study on permeability characteristics of red sandstone under cyclic seepage pressures," Rock and Soil Mechanics, vol. 5, pp. 937-943, 2015.

[24] G. Z. Sun, Y. B. Jing, R. L. Zhang, and L. G. Wang, "Permeability of coal samples containing methane under cyclic loadingunloading of axial stresses," Chinese Journal of Rock Mechanics and Engineering, vol. 35, no. 5, pp. 928-938, 2016.

[25] X. Y. Wang, H. W. Zhou, J. C. Zhong, L. Zhang, C. Wang, and L. An, "Study on energy evolution and permeability character- istics of deep coal damage under triaxial cyclic loading and unloading conditions," Chinese Journal of Rock Mechanics and Engineering, vol. 12, pp. 2676-2684, 2018.

[26] W. J. B. Sun, Y. J. Zuo, Z. H. Wu, and Y. F. Xu, "Experimental study on seepage-damage evolution of shale," China Mining Magazine, vol. 26, no. 3, pp. 142-145, 2017.

[27] C. Yan, Y. Cheng, F. Deng, and J. Tian, "Permeability change caused by stress damage of gas shale," Energies, vol. 10, no. 9, pp. 1350-1360, 2017.

[28] X. P. Zhou, H. Cheng, and Y. F. Feng, “An experimental study of crack coalescence behaviour in rock-like materials containing multiple flaws under uniaxial compression," Rock Mechanics and Rock Engineering, vol. 47, no. 6, pp. 1961-1986, 2014.

[29] Y. Z. Huang and E. Z. Wang, "Experiment study on coefficient of sensitiveness between percolation and effective for low pressure for low permeability rock," Chinese Journal of Rock Mechanics and Engineering, vol. 26, no. 2, pp. 410-414, 2007.

[30] D. S. Yang, W. Wang, W. Z. Chen et al., "Investigation on stress sensitivity of permeability in a natural fractured shale," Environmental Earth Sciences, vol. 78, no. 55, pp. 1-10, 2019. 